\title{
Map of experiments
}

LONDON [UK]

Makers of London, Unite!

65

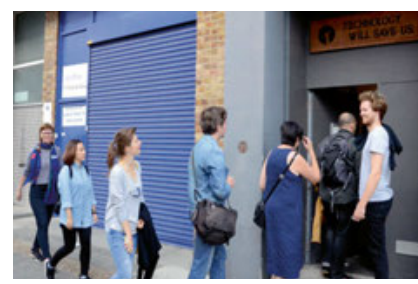

BRUSSELS [BE]

Making a Splash

95

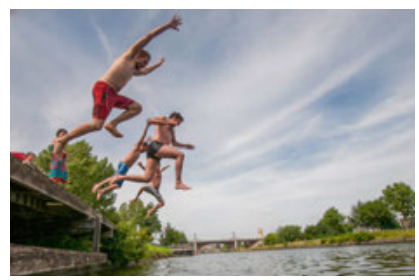

BILBAO [ES]

Public Art to Build Bridges

141

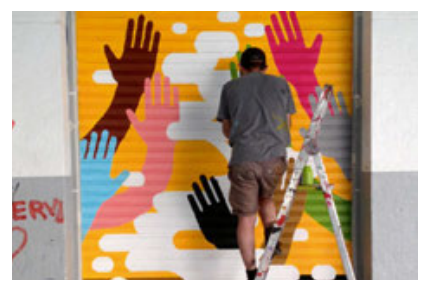

SAINT-ÉTIENNE [FR]

A Space Odyssey

29

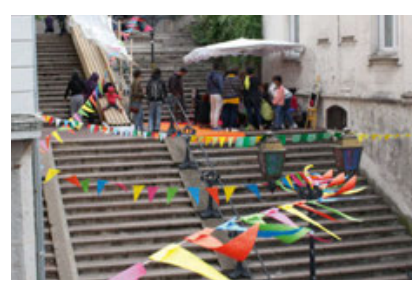

MILAN [IT]

Design and Theatre Meet in No Man's Land

41

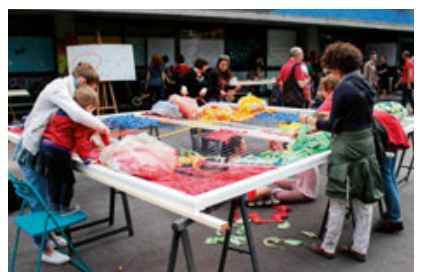


Sharing Spaces for Social Learning

107

\section{GRAZ [AT]}

Benches for the People

119

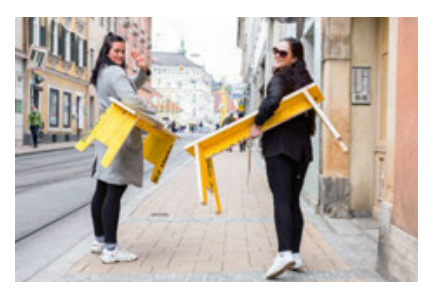

LJUBLJJANA [S]]

Building Community on the Outskirts of the City

51

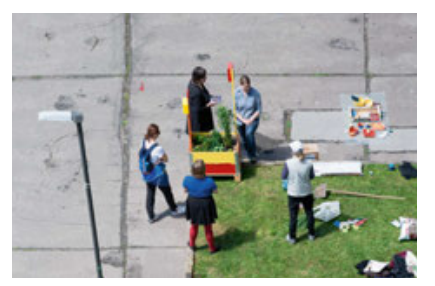

CIESZYN [PL]

Transforming a Bus Station into a Laboratory for CityMaking

75

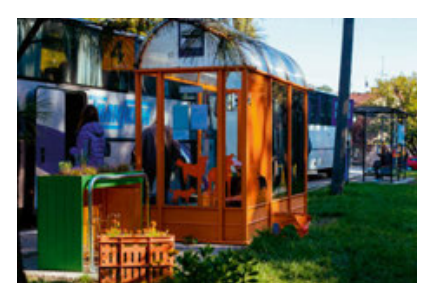

TALLINN [ES]

Relaxing in the Wilderness and the City

131

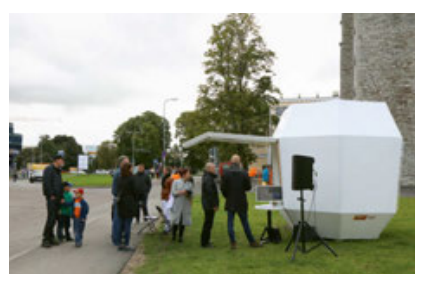

BELGRADE [RS]

Root-and-Branch

Transformation

85

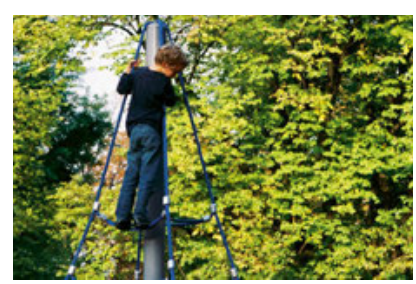


